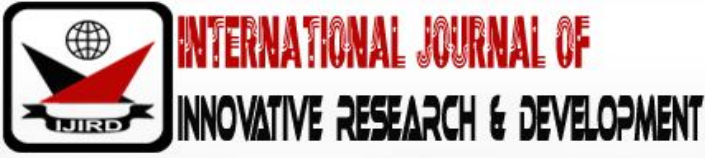

ISSN 2278 - 0211 (Online)

\section{Evaluating Problems Encountered by Small and Medium-Sized Enterprises (SMES) in Accessing Financial Support from Commercial Banks in Botswana}

\author{
Guruwo Paul T. \\ Lecturer, Department of Entrepreneurship, BA ISAGO University, Gaborone, Botswana \\ Samuel Segolame \\ Lecturer, Department of Business Management, BA ISAGO University, Gaborone, Botswana
}

\begin{abstract}
:
The study examined problems faced by small and medium sized enterprises (SMEs) in gaining access to financial support from commercial banks in Botswana. The main objective of the study was to analyse the cumulative adverse effect of SMEs in Botswana failing to access funds. This study adopted the descriptive survey research using fifty structured questionnaires distributed to fifteen SMEs operating in Gaborone. Data was analysed using descriptive statistics and presented using bargraphs. Simple random sampling was used to accord each participant an equal chance of being included in the sample and the SPSS Version 22 software was used to interpret the collected data. Cronbach's Alpha was used to scrutinize for sufficiency, consistency, intensity and suitability of the research questionnaires. All the measurement instrument's multi-item scales were tested for validity and reliability and a Cronbach's alpha of 0.50 was considered as reliable. The results exposed that, SMEs face problems of lack of collateral requirements, infrastructural constraints, and inadequate technical as well as managerial skills. The government was encouraged to increase SMEs support initiatives like lower interest rates incentives from financial institutions.
\end{abstract}

Keywords: Small and medium scale enterprise, financial support, economic growth, commercial bank

\section{Introduction}

Small and medium sized enterprises (SMEs) significantly contribute to economic growth and development of a country. However, they suffer a great deal when they lack financial backup to support their developments and expansion. Although the government of Botswana has put in place some government schemes like Citizen Entrepreneurial Development Agency (CEDA) which are available to offer financial assistance to SMEs, there continue to be inadequate finances resulting in lack of growth and expansion in these enterprises. Commercial banks are some of the major avenues for providing credit to SMEs but only under certain requirements. SMEs often tend to lack tangible collateral assets that banks desire. It is against this background that motivated the researchers to evaluate some the problems encountered by SMEs in accessing funds from commercial banks in Botswana.

The challenges brought forth with commercial banks when financing SMEs sparked debate and growing interest from researchers, policy makers and entrepreneurs arguing for commercial banks to reconsideration their policies due to the relative importance SMEs in both developed and developing countries play in the economy. The important role played by the SMEs in Botswana has been increasingly realized over the past years not only in the vitality of the business sector, but also in terms of employment creation, income generation and output growth to the country's gross domestic product, (GDP). SMEs play a crucial role towards achieving industrial and economic development objectives of any economy. The share of SMEs in employment tend to be higher in emerging economies, which are typically more focused on small scale production, than in the developed countries. The problem of inadequate finances has affected SMEs' effective performance. It is a wide spread concern that the banking system is not providing enough support to SMEs and to new economic initiatives in particular to the expansion of small businesses in most emerging economies. It is noted that the commercial banks which retained liquidity levels in excess of regulation has shown reluctance in financing SMEs Sacerdoti, (2005).

Bronson, (2006) argues that, financing SMEs is difficult because their opaqueness, implying difficulty in ascertaining their capacity to payback and or the willingness to pay. This opaqueness particularly undermines serious engagement from lending institutions. To worsen the situation, SMEs particularly in developing countries are more likely to be informal and that 
poses additional obstacles since commercial banks find it difficult to lend to firms that do not reliably report their full financial activities.

It is recognized that the availability of financial capital to SMEs is a pre-requisite for rapid economic development. Commercial banks therefore have a vigorous role in financing these small businesses since it was noted that the they were not accorded significant importance in developing countries of Africa until 1975 Mashly and Stanley, (2009). Nonetheless, in Botswana inadequate credit facilities has been a major impediment of small scale enterprises and for this reason many of them are either proprietary on partnership and so cannot obtain funds from commercial banks. Resultantly, they are either financially starved or at best obtain funds on extremely unfavourable terms from sources other than financial institutions. The problem of finance hinders SMEs from operating in a profitable competitive market. In order for small scale enterprise to obtain a loan from commercial banks, they need to have a track record and must show sales growth, assets and some reasonable sales projections for their business, requirements which lack from the majority of the operating SMEs.

Stieglitz and Weis (2001) observed that SMEs with opportunities to invest in positive net present value projections may be denied a chance from doing so because of adverse selection and moral hazard problems. Adverse selection problems arise when potential providers of external finance cannot readily verify whether the firm has got access to quality projects or not. Moral hazard problems are associated with the possibility of SMEs diverting funds available to them to find alternative projects or develop the propensity to take excessive risks due to some incentive structure in the system.

On the other hand, since SMEs do not have access to public capital markets, they naturally depend on banks for funding, apart from the government programmes. Dependence on banks makes them even more vulnerable for simple reasons that shock in the banking system which may have a significant impact on the supply of credit to SMEs. Shocks to the economic environment in which both banks and SMEs exist can also significantly affect the willingness and capability of banks to lend to them.

The study was conducted in Gaborone, the capital city of Botswana that houses the central businesses, a large number of the country's population, and it is where most developments are found. The study focused on few commercial banks around Gaborone, such as First National Bank Botswana (FNBB), Barclays Bank of Botswana and Standard Chartered Bank. The study also concentrated on employees from both commercial banks and SMEs around Gaborone.

\section{Literature Review}

\subsection{Small to Medium Scale Enterprises}

The definition of small and medium enterprise (SME) varies according to different factors. Chittithaworn et al. (2011) expressed that an enterprise is considered to be an SME based on value of assets or number of full-time employees. Both Chittithaworn et al. and the Republic of Botswana, (1998) agreed on a micro business being one with six or less employees, that have a turnover of up to P60 000 a year. On the other hand a small business was defined as one with less than 25 employees and with an annual turnover between P60 000 and P1 500 000. Furthermore a medium sized enterprise was thought to be one with between 25 and 100 employees and an annual turnover of between P1.5 million and P5 million.

Robert (2008) is of the view that, just like large scale enterprises, SMEs assemble finished goods and mostly depend satisfactorily on imported raw materials and equipment and therefore tend to suffer from almost the same problems. Nonetheless the size, nature, features and isolation of the SMEs made them more vulnerable to these constraints. Hence the rate of business failures is dominant among SMEs. Sowa, (2003) postulates that access to bank credit by small SMEs has been an issue repeatedly raised by numerous studies as a major constraint to industrial growth. Both authors mostly indicated that one of the major reasons why SMEs lack access to commercial banks' loan facilities is their inability to pledge acceptable collateral.

The chairman and CEO of Bank of Africa, Paul Derreumaux highlighted that there are three main issues that blocks the flow of credit from banks to SMEs. He outlined them as lack of equity in small scale enterprises, lack of organisation in terms of human resource, accounting and administrative management among others as well as the firm's lack of vision. Derreumaux also signalled that most SMEs are developed without any in-depth analysis of the market or competition, which often leads to disillusion in terms of the firm's turnover and consequently, in the repayment capacity for bank loan. Ekhator (2007) is of the view that the major problems of SMEs sometimes arise from the nature and characteristics of the enterprise. On another note, Babajide (2007) believes that SMEs do not only suffer the major problem of avenues of sourcing funds, but also the accessibility of these funds, while on the other hand, Mordi (2005) considers that funding is not the major problem faced by SMEs. The latter prefers to view the situation from two perspectives, thus; most SMEs find it difficult to differentiate between the owner of the business and the business itself. He also pin points out that a lot of SMEs run the business without financial accountability and show gross ignorance about the need to seek equity participation. The second perspective as viewed by Mordi (2005) is a problem identified as market protection for SMEs viewed from the policy side where the government does not usually offer market protection for SMEs. In addition, local manufactures face stiff competition from their foreign counterparts consequently producing an economy of scale that gives them unfair advantage, (Mordi, 2005).

Furthermore, managerial skills is one other problem to accessing financial support for financing SMEs. According to Lapar and Graham, (2008) and Fatoki and Odeyemi, (2010), managerial competencies are sets of knowledge, skills, behaviours and attitudes that contribute to personal effectiveness. Fatoki and Odeyemi cited lack of managerial skills as the main reason for SMEs to fail in accessing finance from commercial banks probably because commercial banks requires sound 
negotiation financial management skills to win confidence of financial support. This therefore suggested that managerial competency impacted on access to finance by new SMEs. Ras and Pretorious (2007) states that countries need to provide training programs in order to meet the demand of fostering SMEs. Labuschgn and Van Niekerk (2006) state that lack of managerial skills accounts for $80 \%$ of South African SMEs. Management incompetence in SMEs may include but is not limited to the following scenarios; lack of management information, poor planning skills, insufficient control and unsatisfactory management of finances. Khumalo (2004) points out that many SMEs have poor management skills and mostly fail to keep proper records. Planning is considered option rather than a policy in most SMEs, thus their high failure rate. Ray and Hiduke (2009) reckon that anyone without knowledge of business management and who fails to exercise cash flow management is responsible for his or her own downfall.

Furthermore, entrepreneurs need to acquire the necessary education level for them to be able to request for financing. Education helps to enhance the exploratory skills, improves communication abilities and foresight, Dobbs \& Hamilton, (2007). Some previous researchers have explored how the managerial education effort affects the access to credit. Kumar and Francisco (2005) found a strong effect of education on the access to financial services.

Infrastructure constraint is another problem encountered thus far. As a developing country, Botswana's basic infrastructure is poor and the issue has remained unsolved for a while. This has partly restrained the capacity of SMEs since the development of small industries is undesirably affected by a variety of factors and inadequate provision of essential services such ceaseless electric power outage, under-utilisation of capacities, telecommunications, access roads and water supply, just to name a few that largely impacts on productivity.

It has been established that most SMEs resort to private provisioning of these facilities at great costs, thereby reducing their available operating funds. A World Bank study (2003), estimated that such cost accounted for 15-20\% of the cost of establishing SMEs in Botswana. This is likely to be much higher today, given the high level weakening of our basic infrastructure. SMEs need contemporary managerial skills that are coupled with technical expertise in-order to source our resources to enable SMEs operators to effectively and efficiently perform without or with little hindrances. It is therefore crucial that the government of Botswana and the organised private sector jointly ensure that proper assistance is put in place for the proper functioning of the SMEs.

\subsection{Causes of Lack of Financial Support}

Kapunda (2016) established that SMEs face challenges of insufficient internal funding and thereby tend to resort to external funding theory of investment which he argued is essential for investment. Such external funds include grants, loans, sale of bonds and other forms of borrowing (Kaplan and Warren 2010; Mutoko 2015). Nonetheless, even after lending SMEs funds, sometimes they fail to repay loans and this leads to bankruptcy as well as SMEs feeling more insecure and ultimately closing down. This then may lead to banks ceasing funding the SMEs. According to Kapunda, CEDA, for example, had to reduce funding during the 2009 recession period due to increased SMEs defaulting on repayments (CEDA 2012; Kapunda 2016).

Information asymmetry is another problem faced by banks in their pursuit to finance SMEs. Information asymmetry makes it too costly for banks to obtain accurate information on borrowers and to monitor actions of the borrowers, Barnejj (2008). This is due to that most entrepreneurs typically possess privileged information on their business that cannot be easily accessed by commercial banks. Some SMEs tend to provide information that lacks detail and rigor. Consequently, the likelihood of attainment of the project becomes unknown to the bank but known to the firm due to this information asymmetry. The borrowers may choose to shift from safe projects that yield standard returns to higher risk projects that promise higher but with lower probability of success, and the bank has no control at all over such actions of the borrowers. Banks therefore, choose and use interest rates as a screening device for differentiating bad risk over good risk and owing to this, tend to pose more anomalies for either upcoming or existing SMEs. Such information asymmetry problems are often intensified by the low level of education of SMEs. Anderson (2004) found that this problem is predominantly severe in developing countries.

Further, collateral requirements which is an obligatory condition for granting a loan, is yet another cause of lack of financial support. It serves as the last resort for recovery of the loan in case of loan default whereby the bank can sell collateral obtained to recover the balance or part of the loan. Conversely, it has been noted that small businesses often face difficulty in providing sufficient and good quality collateral to commercial banks. The banks typically agrees to accept collateral in the following forms; real property, products or valuable assets. Suder (2009), has recognised that commercial banks are less inclined to accept the balance of checking account, finished commodity, guarantees and other company or a bank and securities as collateral, rather, are more inclined to accept collateral in form of real property, products or valuable assets. Chan and Kanatas (2005) are of the view that collateral simply reduces the information asymmetry between the SMEs and the financer. At times, SMEs may have collateral which it value does not match the finance requested and this becomes a problem to the bank and the SME.

\subsection{The Consequences of Problems Faced By SMEs}

Changes in the environment lead to problems that are attached to SMEs in Botswana and eventually, such problems lead to consequences which may either impact on the SME itself or the financer of the business. Chittihaworn (2011), stipulates that every SME respond differently to environmental changes and therefore every consequence must be dealt with individually. 


\subsubsection{Sources of Financing Smes}

SMEs get their finances from various sources. Wasonga (2008) notes that $75 \%-90 \%$ of SMEs heavily rely on the informal sector funding which mainly comprise of one's internal savings, retained earnings and borrowing from family and friends. On the other hand, 3\%-18\% of people have access to formal sector financing, referring to banks and venture capitalists. It was established that generally, SMEs in developing countries have not been successful in tapping funds from the formal financial sector yet. If they did, it is usually at a relatively high cost. This signals that the problem of less people having access to formal sector funding eventually results in high cost of accessing funds. However, particularly in Botswana, to avert these numerous constrictions to the growth of SMEs, the government initiated programmes such as (CEDA), that provides an all-inclusive approach to the development and promotion of feasible justifiable citizen owned enterprises. CEDA does this through the provision of financial assistance in the form of loans at subsidised interest rates.

In other developing countries, restrictive government regulations led to highly concentrated and uncompetitive banking sector. This reinforces the tendency to adopt very conservative lending policies or to charge high interest rates Biggs, (1996). Begger (2004) advances that if banks can thrive with a stable pool of well-established clients, then they have no real motivation to improve the range of financial products, particularly, no motivation to go down market, to meet the needs of small businesses. To add on, insufficiently developed legal systems effectively prevent the development of certain financing instruments, including the use of collateral as a risk mitigating element Anderson, (2004). Lamoreaux (2000) states that there is a lack of mechanism for collecting and exchanging information on payment performances. Unavoidably, this aggravates the information asymmetries between small scale enterprises and prospective lenders. SMEs inexplicably suffer from a wide range of institutional constraints.

Hoff et al (2007) realised that banks should design ways of providing loans to business, especially SMEs. It emanates from the realisation that the availability of financial capital is a pre-requisite for rapid economic development. According to Hoff et all., commercial banks have numerous ways to get involved in the small-scale enterprise finance, ranging from the creation or participation in SMEs finance investment funds, to the creation of a special unit for financing small SMEs within the bank. Diamond (2012) discussed the services provided by the commercial banks in financing SMEs as follows;

- Short term loans compatible with SMEs business and income patterns

- Repeated loans, where full repayment of one loan bring access to another, and where the size of the loan depends on the clients' cash flow

- Very small loans or bank overdraft facilities are also appropriate for meeting the day to day financial requirements of small businesses.

- Factoring and invoice discounting, asset finance (including commercial mortgages), and equity finance, all being within the framework of a customer friendly approach.

Banks need to be cognizant of their role as important agents of economic development, and not confine themselves to a narrow range of activities or customers, especially given the very high rate of profits earned by banks. Guido, (2007), explained that there is widespread evidence and experience showing that broadening access to financial products and services benefit individuals, businesses, and the economy as a whole. Access to savings products, credit and transaction services enables people and businesses to accumulate financial assets, invest, spread risk, and make payments cheaply and efficiently. There are well established links between the size and scope of the financial system and the rate of economic growth.

\subsubsection{Theoretical framework}

Many theories have raised the issue on the financing gap for SMEs meaning that there is a good number of small scale enterprises to whom when given access to credit could use it profitably to grow their businesses but cannot obtain credit from commercial banks because of the inability of the SMEs to meet the rigorous requirement of these financial institutions.

\subsubsection{The Agency Theory}

The agency theory of Jensen and Meckling (1976) is based on the conflict between shareholders and management of the firm and debt holders. Lending and borrowing are financing agreements that create financial obligations on the two parties. Consequently, the supply of funds to businesses is influenced by contracts that create appropriate incentive for both the supplier and user of funds. The ideal contract in the researcher's perspective is one that is based on trust instead of risk. Such situation will induce the borrower to act in the best interest of the supplier of funds. If such contracts are created, the supply and demand for funds will be brought into balance since there is mutually beneficial relationship between the supplier and user of funds Mensah (2004). In this regard, it is the researcher's proposition that any financing gap would be mediated. Sogob and Mira (2015) are of the disposition that because SMEs are mostly own-managed, there is a likelihood of them not to be impacted considerably by the conflict between the shareholder and the managers. Nevertheless, Abor and Biepke (2009) posit that the agency between the owners and the debt holders may be mainly severe for SMEs. It is intense that agency problem occur between lenders, as principals, and borrowers, as agents because the contracting parties cannot easily observe or control each other and because contracts cannot be enforced without incurring costs. Thus, contractual frictions can arise because of moral hazard or adverse selection. 


\subsubsection{Adverse Selection}

This refers to a market process in which undesired result occurs when buyers and sellers have asymmetric information. In most cases, the bad products are what are mostly selected as compared to the good products e.g. a commercial bank that sets one price for all its checking account customers runs the risk of being adversely selected against by its low balance, high activity and hence low profitable customers, Khandker, (1996). Adverse selection arises from the fact that risky borrowers are more eager for loans, especially at high interest's rates, than safe borrowers.

\subsubsection{Moral Hazards}

Moral hazards arise from the fact that people are basically self-interested. If given the opportunity by banks, borrowers tend to default on contracts by engaging in risky activities with, or even outright stealing lenders' wealth, (Udell, 2003). A borrower may have the means to repay the loan but default on it anyway so that she can use the resources for personal benefit. In order to reduce the risk of default due to information asymmetry, lenders must create information about borrowers. According to Rosent (2003), banks created information by screening discount applicants to reduce adverse selection and by monitoring loan recipients and requiring collateral to reduce moral hazard. Screening procedures included examining the applicant's credit history and current financial condition.

The commercial banks will finance the SMEs with the intention of helping them grow in their small scale trends. In most cases this does not happen. They rather use the loan offered to them for their own purpose which is far from the reasons of the offered loan. However, the responsibility of proper utilisation of borrowed funds lies with the borrower.

\subsection{Factors Considered by Commercial Banks When Granting Loans to SMEs}

Darfor (2011), noted that small business sector is now increasingly an important source of profitability for the financial institutions, predominantly commercial banks. It is therefore necessary for small business operators when borrowing to develop an understanding of the decision criteria used by financial institutions in order to increase the probability of getting their loans accepted by fulfilling the required criteria. Darfor (2011), carried out a study and states that when loan managers are deciding on whether to accept or reject a loan application from small business operators, they look at the intended purpose of the loan, which constitute of the business plan. The business plan must indicate that indeed the applicant's business is solid and you have a strong track record performance. The loan applicant must convince the bank of what they would really do with the money. The bank also looks at the type of business activity, size of the loan in relation to the size of the business and also the availability of appropriate collateral. All the above mentioned factors are critical on the criteria list. On the other hand, it must be noted that different commercial banks adopt distinguished criteria for bank loan application. The bank may adopt the following factors in the section list; collateral, guarantee, maturity and schedule of repayment ,Ulrich and Arlow, (2008); collateral, credit history, initial capital, managerial experience and the bank policy Jones (2002); security, financial strength, business ability and honesty Fertuck (2002); profitability, financial stability and liquidity, Berry et al., (2003); training experience, equity stake, gearing and profitability, Deakins \& Hussian,(2004); Fletcher 1995), and quality of management and risk default Rosli (2005).

\section{Methodology}

Descriptive survey research was used to expose the challenges faced by SMEs in Gaborone and their adverse effect. Convenience sampling of 30 employees from 15 SMEs around Gaborone was selected for the study due to time and transportation constraints. Approximately 50 questionnaires with both close and open ended questionnaires were distributed with a maximum of 3 questionnaires per SME. Simple random sampling was used to accord each participant the same chance of being included in the sample and the SPSS Version 22 software was used to analyse the data. Cronbach's Alpha was used to scrutinize for sufficiency, consistency, intensity and suitability of the research questionnaires. All the measurement instrument's multi-item scales were tested for validity and reliability and a Cronbach's alpha of 0.50 as was considered as reliable. 


\section{Data Analysis}

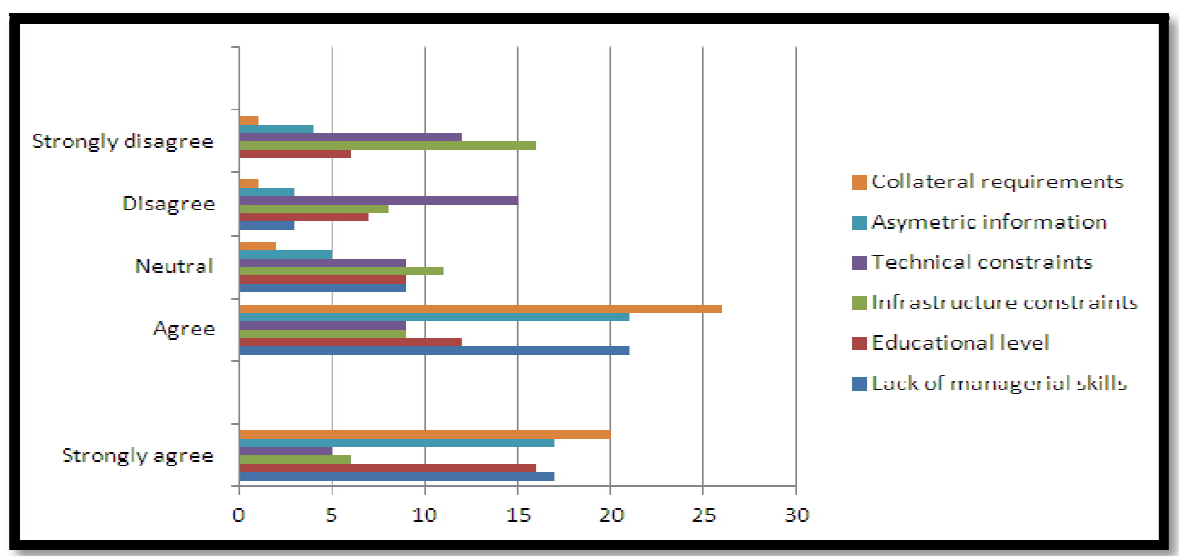

Figure 1: Problems Faced by Small Medium Enterprises in Accessing Finances

Fig.1 above shows that the majority of the respondents agreed on collateral requirements followed by asymmetric information from commercial banks being the major challenge they faced. A sizeable number of respondents seemed to disagree to technical constraints as a reason for not accessing banking finances. One third of the respondents strongly disagree on infrastructure being a constraint to them accessing financial support, whilst another one third strongly agreed that educational level is one of the major reasons why SMEs can't access funds from commercial banks. Two fifths of the respondents agreed to managerial skills, being another major stumbling block.

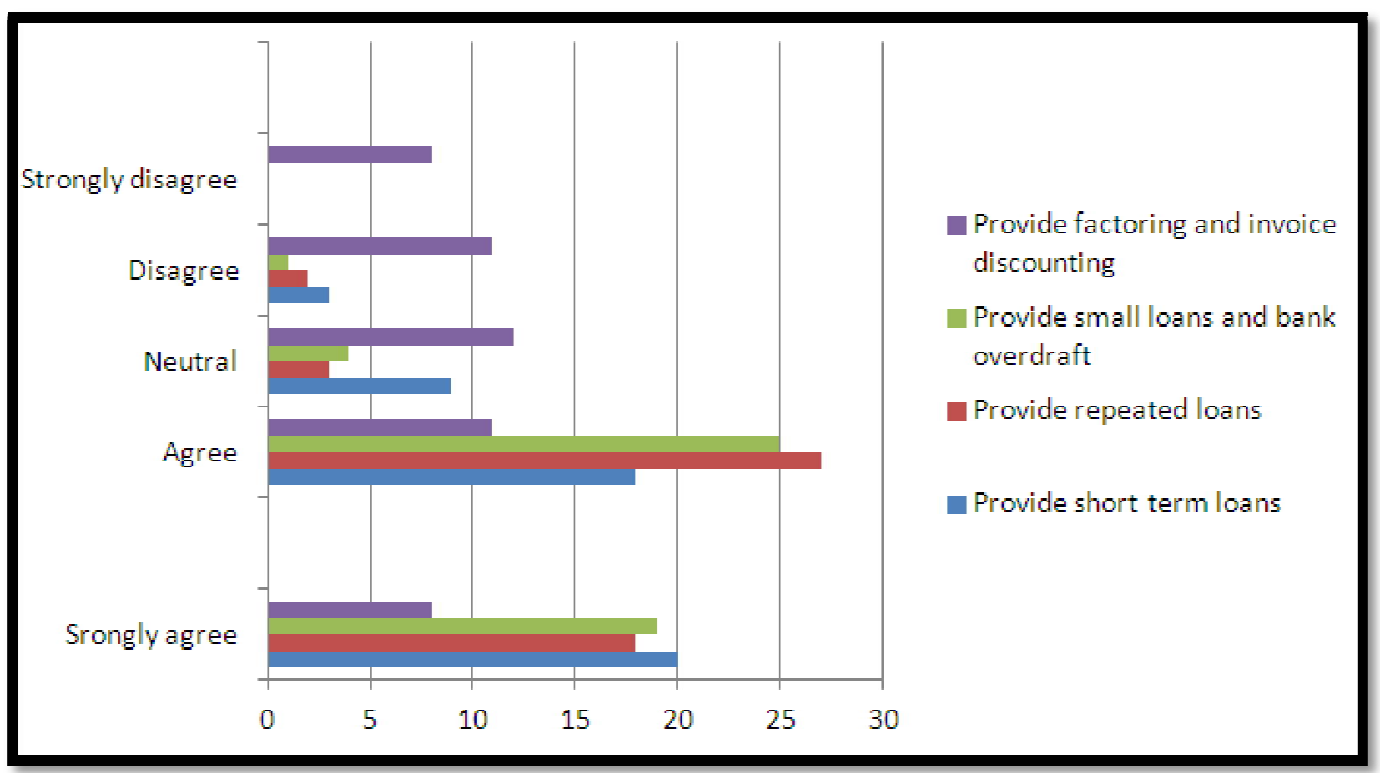

Figure 2: Role Played by Commercial Banks in Financing SMES

An analysis of Fig.2 above revealed a quarter of the respondents being neutral on factoring and invoice discounting as a role played by commercial banks on financing small medium enterprises. However, half of the participants concurred that banks provide small loans and bank overdrafts, and assumed that banks do so to allow for continuous operation of the SME. Banks may be may be giving access mainly to short loans to avoid major risk from defaulters and also since they are repayable in a short. 


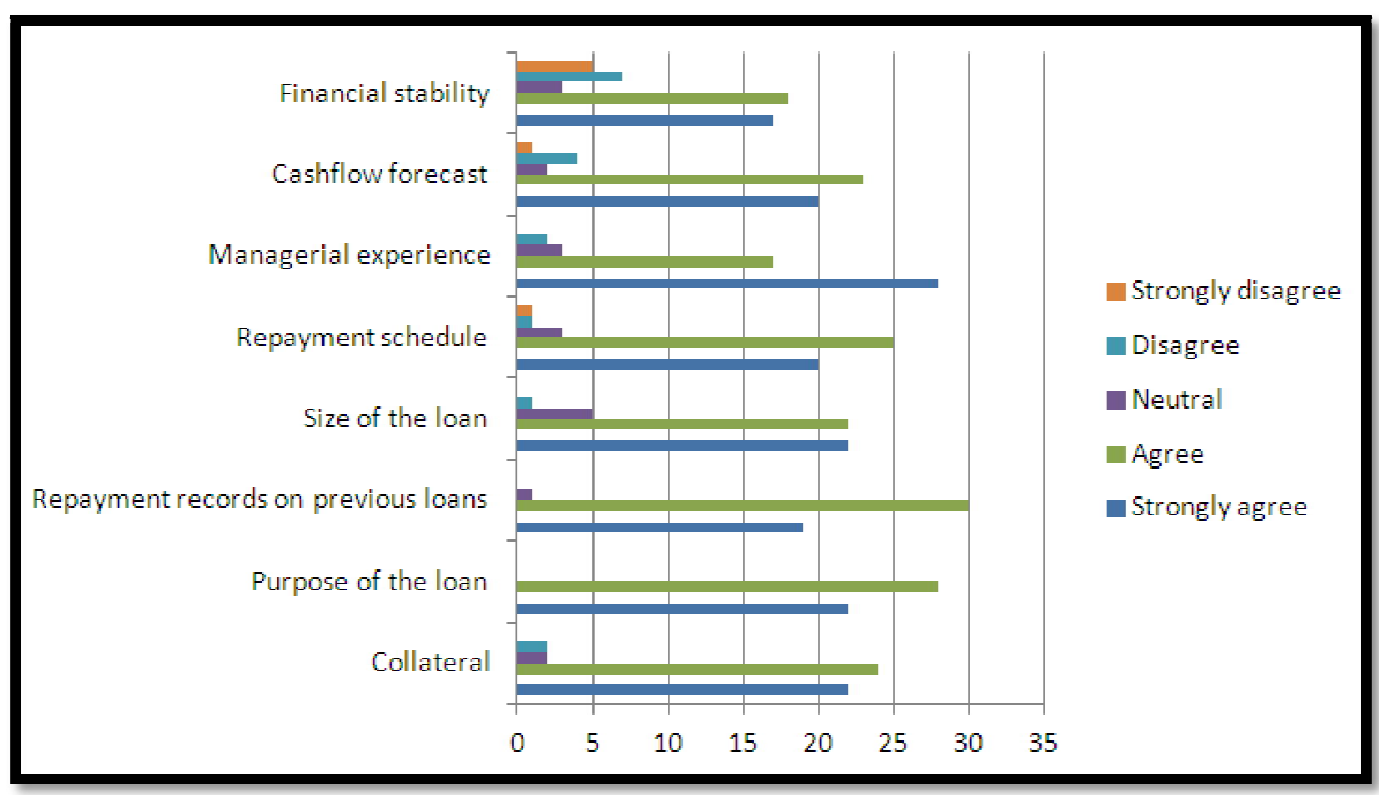

Figure 3: Factors Considered by Commercial Banks When Granting Loans to SMES

Fig.3 above depicted $48.0 \%$ participants agreed that collateral is one of the main factors considered by commercial banks when lending out loans to SMEs. The analysed results indeed confirmed that banks required collateral from SMEs, to cushion from defaulters. However, confirmed that the purpose of the loan, is quite significant thus a business plan needed beforehand. Two thirds of the population mentioned that a repayment record on previous loans was crucial on the banks' analysis. On the other hand, a further two thirds confirmed a repayment schedule is also needed and four fifth of the participants either agreed or strongly agreed that a forecasted cash flow was needed. Overall, $70 \%$ of respondents concurred that banks do look at the financial stability of the SME before they grant them a loan. Most commercial banks were cited as considering the managerial skills of an SME when granting a loan, leaving respondents thinking that banks prefer perfectly managed businesses to make profits, as a way to reduce chances of default.

The major findings from the research are summarised as follows:

The major problem encountered by small medium enterprises when trying to accesses funds from commercial banks is collateral which is required from them. There are a certain number of roles played by commercial banks in financing SMEs like providing repeated short loans, bank overdrafts, factoring but the major role played by commercial banks is identified to be proving short repeated loans as they are repaid in a short period of time hence the chances of defaults are very low. When financing small medium enterprises, the commercial banks consider a number of factors like collateral, purpose of the loan, repayment schedule, cash-flow forecasts and previous repayment records, but the most highly considered factor was the repayment records on previous loans and collateral since banks wanted to avoid high risk people.

\section{Conclusions and Recommendations}

The study undoubtedly discovered that SMES could potentially boost the country's Gross Domestic Product (GDP), reduce poverty and unemployment and diversify the economy. To realistically address problems of unemployment and poverty, the government was advised to focus on SMEs, making them the economic policy priority by providing necessary incentives, education, infrastructure and a general conductive environment for the development of SMEs. Botswana's institutions of higher learning were advised to address the skills and technical education gap required by enterprises in accessing finance from commercial banks so that the ultimate objective of entrepreneurial and commercial development of the nation can be achieved. Commercial banks were asked to slightly relax collaterals as the overriding condition for granting credit facilities to SMEs.

Also as a way to support and encourage SMEs to develop the national economy the government was encouraged to introduce tax incentives to banks involved in SME lending.

\section{References}

i. Abor, J, Biekpe, N. (2009). "How do we explain the capital structure of SMEs in sub-Saharan Africa? Evidence from Ghana", Journal of Economics Studies, Volume 36 Iss: 1, pp. 83-97

ii. Babajide A.K. (2007): "Funding of SME: Sourcing of Funds and Problem Limiting Access." Paper Presented AT THE 4"TH Partners Forum of the Public Practice Section of the Institute of Chartered Accountants of Nigeria (ICAN).

iii. Banerjee, Sanjibani (2008), "Credit Rationing with Neo-Classical Banks and Production Firms" http:/ / artsci.wustl.edu/ econgr/ gradconference/ 08/ SanjibaniBanerjj.pdf 
iv. Chittithaworn, C., Islam, M. A., Keawchana, T., \& Yusuf, D. H. M. (2011). Factors affecting business success of small \& medium enterprises (SMEs) in Thailand. Asian Social Science, 7(5), 180.

v. Diamond, H. (2007), "Analysis of mobile banking for financial inclusion: Tanzania

vi. Ekhator V.E. (2007): "Role of Small and Medium Scale Enterprises in the Nigerian Economy". Paper Presented to the Department of Public Administration, University of Abuja.

vii. Fatoki, O., \& Odeyemi, A. (2010). "Challenges of access to markets and opportunities for small, medium and micro enterprises. Which new small and medium enterprises in South Africa have access to bank credit?", International Journal of Business and Management, 5(10), 128.erprises (SMMEs) in Botswana. European Scientific Journal, ESJ, 10(10).

viii. Hoff, K. and J.E. Stiglitz (1990), "Imperfect Information and Rural Credit Markets- Puzzles and Policy Perspectives", The World Bank Economic Review, 4 (3).

ix. Hoff, Makteike H; Virginia, B;Ray, C; Jesse, L, - On the Fronties of Finance Investing In Sustainable SMEs in Emerging Markets, A Discussion Paper for the Geneva Private Capital Symposium September 24th $-25^{\text {th }}$, 2007, Boston College Institute For Responsible Investment Mareikel Hussles, World Resource Institute. Available online:http:/ / hausercenter.org/ iri/ wp-content/ uploads/ 2010/ 05/ On-the-Fronties-of-Finance,pdf.Accessed 25/ 7/ 13.

x. Jensen, M.C. and W.H. Meckling (1976), "Theory of the Firm: Managerial Behaviour, Agency Costs and Ownership Structure, Journal of Financial Economics", pp. 305-360.

xi. Khandker H. (1996), "Effects of mobile banking on customer satisfaction: international journal of innovative research, Vol. 3, Issue, pp7.

xii. Kapunda, S. M. (2016). SME Finance, Development and Trade in Botswana: A Gender Perspective. Business Management Review, 11(1).

xiii. Khumalo, G. (2004). Fragile Foundation: prospects for black building contractors, research report no.37. Development Policy Series. Johannesburg: Centre for Policy Studies.

xiv. Lapar, M.L.A. and D.H. Graham (2008), "Credit Rationing under a Deregulated Financial System” Working Paper Series No. 88- 19, http:// www.3.pids.gov.ph/ ris/ wp/ pidswp8819.pdf.

xv. Mashly, R. and Stanley, D, (2009), "Support for rural small businesses in Limpopo Province, South Africa, Development South Africa.

xvi. Mensah, (2004). A review of Financing Schemes in Ghana. Final Report for UNIDO Regional workshop of Financing Small and Medium Scale Enterprises, Accra, Ghana.

xvii. Mordi F (2005): “Why Government Must Protect Small and Medium Scale Enterprises”. Financial Standard, August 19.

xviii. Sacerdoti, E. (2005). Access to Bank Credit in sub-Saharan Africa: Key issues and Reform Strategies. International Monetary Fund (IMF) Working Paper WP/ 05/ 166, August.

xix. Sorgob- Mira, F., How S.M.E. (2005). "Uniqueness affects capital structure: evidence from a 1994-1998 Spanish data panel", Small Business Economics, Vol. 25 No.5, pp.447-57.

xx. Sowah N.K (2003), Comments on "The Golden Age of business: The Role of The Banking sector", CEPA Research Working Paper.

xxi. Stiglitz, J. Weiss, A., (2001). "Credit Rationing in Markets with Imperfect Information", The American Economic Review, 71, pp. 393-410.

xxii. World Bank, - Global Financial Indicators, Economic Outlook, Washington: IMF, Washington, D.C. 2003. 